\title{
Genetic and biochemical study of dual hereditary jaundice: Dubin-Johnson and Gilbert's syndromes. Haplotyping and founder effect of deletion in ABCC2
}

Lenka Slachtova, Ondrej Seda, Jana Behunova, Martin Mistrik and Pavel Martasek

European Journal of Human Genetics (2016) 24, 1515; doi:10.1038/ejhg.2016.51

Correction to: European Journal of Human Genetics (2016) 24, 704-709; doi:10.1038/ejhg.2015.181; published online 9 September 2015

Post publication, the authors realised that they had omitted the following acknowledgement:
PM is also supported by Grant Agency of Czech Republic (14-36804G).

The authors would like to apologise for this omission.

\section{Guidelines for diagnostic next-generation sequencing}

Gert Matthijs, Erika Souche, Mariëlle Alders, Anniek Corveleyn, Sebastian Eck, Ilse Feenstra, Valérie Race, Erik Sistermans, Marc Sturm, Marjan Weiss, Helger Yntema, Egbert Bakker, Hans Scheffer and Peter Bauer

European Journal of Human Genetics (2016) 24, 1515; doi:10.1038/ejhg.2016.63

Correction to: European Journal of Human Genetics (2016) 24, 2-5; doi:10.1038/ejhg.2015.226; published online 28 October 2015
Following the publication of this article, the authors wish to append a Supplementary file. This information can be found on European Journal of Human Genetics website http://www.nature. com/ejhg.

\section{Years of predictive testing for Huntington's disease: the experience of the UK Huntington's Prediction Consortium}

Sheharyar S Baig, Mark Strong, Elisabeth Rosser, Nicola V Taverner, Ruth Glew, Zosia Miedzybrodzka, Angus Clarke, David Craufurd, UK Huntington's Disease Prediction Consortium and Oliver W Quarrell

European Journal of Human Genetics (2016) 24, 1515; doi:10.1038/ejhg.2016.81

Correction to: European Journal of Human Genetics (2016) 24, 1396-1402; doi:10.1038/ejhg.2016.36; published online 11 May 2016

Post online publication the authors realised that they had made an error:
The sentence on page 2: 'In the first 5-year period.........but this changed significantly in the last 5 -year period with $51 \%$ positive and $49 \%$ negative $\left(\chi^{2}=20.6, P<0.0001\right)$ ' should read: 'In the first 5-year period.........but this changed significantly in the last 5-year period with $49 \%$ positive and $51 \%$ negative $\left(\chi^{2}=20.6, P<0.0001\right)^{\prime}$. 


\title{
The genomic architecture of NLRP7 is Alu rich and predisposes to disease-associated large deletions
}

\author{
Ramesh Reddy, Ngoc MP Nguyen, Guillaume Sarrabay, Maryam Rezaei, Mayra CG Rivas, \\ Aysenur Kavasoglu, Hakan Berkil, Alaa Elshafey, Ebtesam Abdalla, Kristin P Nunez, Hélène Dreyfus, \\ Merviel Philippe, Zahra Hadipour, Asude Durmaz, Erin E Eaton, Brittany Schubert, Volkan Ulker, \\ Fatemeh Hadipour, Isabelle Touitou, Majid Fardaei and Rima Slim
}

European Journal of Human Genetics (2016) 24, 1516; doi:10.1038/ejhg.2016.96

Correction to: European Journal of Human Genetics (2016) 24, 1445-1452; doi:10.1038/ejhg.2016.9; published online 9 March 2016
The name of Dr Ebtesam Abdalla was inadvertently omitted from the Author list. This has now been added to the article. The affiliations have also been amended accordingly.

The authors would like to apologise for their error. 